\title{
BREVES COMENTÁRIOS ACERCA DA MEDIAÇÃO, CONCILIAÇÃO E ARBITRAGEM NO NOVO CÓDIGO DE PROCESSO CIVIL E NAS NOVAS LEIS
}

\author{
Rachel Lopes Queiroz Chacur, Juliane Nagafugi, Bruno Coelho Gonçalves \\ Universidade do Oeste Paulista - UNOESTE, curso de Direito, Presidente Prudente, SP. E-mail: rachel@unoeste.br
}

\begin{abstract}
RESUMO
No Brasil, ganha cada vez mais espaço a tentativa de resolver os conflitos e buscar um acordo entre as partes antes que elas abram processos e busquem seus direitos a partir de um processo no Judiciário. As medidas de resolução de conflitos, muito utilizadas em outros países, trazem uma nova perspectiva quanto à agilidade e eficácia na resolução do litígio, ou seja, uma solução para a atual lentidão e sobrecarga de processos que existe na esfera do Poder Judiciário. O recémaprovado Código de Processo Civil (2014) traz ao cenário jurídico essa questão, influencia o uso de institutos alternativos para resolução de conflitos, como a mediação e a conciliação. O legislador aposta, conforme se vê, numa forma de cumprir, com eficácia, o compromisso que o Estado tem com a sociedade, e elevar o seu conceito perante esta.
\end{abstract}

Palavras-chave: Meios alternativos - Conflitos - Novo Código de Processo Civil

BRIEF COMMENTS ABOUT MEDIATION, RECONCILIATION AND ARBITRATION IN THE NEW CIVIL PROCEDURE CODE AND THE NEW LAW

\begin{abstract}
In the Brazil, gaining more space an attempt to resolve conflicts and seek an agreement between the parties before they open processes and seek their rights from a process in the judiciary.

The measures of conflict resolution, widely used in other countries, brings a new perspective on the speed and efficiency in resolving the dispute, a solution to the current slow and overloading process that exists in the Legal sphere.

The newly approved Code of Civil Procedure (2014) brings the legal scenario this question, influences the use of alternative institutions for conflict resolution, such as mediation and conciliation. The legislator bet, as it turns out, a way to comply effectively with the commitment that the state has with society, and elevate your concept before this.
\end{abstract}

Keywords: media - alternative - resolution - conflicts - Legal 


\section{INTRODUÇÃO}

A vida em sociedade é regulada por normas, que disciplinam os atos das pessoas a fim de padronizar as ações aceitas e as ações reprovadas pela sociedade. Tais normas são elaboradas pelo Estado, sendo que este possui também o papel de instituir meios de imposição coativa do comando expresso na norma. Se de outra forma fosse, não existindo normas reguladoras e não tivesse um poder coercitivo para aplicá-las, apareceria um grande número de conflitos, que tenderiam a ser resolvidos pelos próprios litigantes, como já aconteceu anteriormente em nossa sociedade. Dessa forma, assim como no período do Direito Romano, as decisões não seriam baseadas no justo, mas na força física ou no poder da influência. À partir do momento em que se chegou à conclusão de que a justiça não deveria ser feita pelas próprias mãos, e sim os conflitos deveriam ser submetidos ao julgamento de autoridade pública, surgiu a necessidade de regulamentar as normas jurídicas processuais. A Constituição Federal de 1988 declarou que todos tinham direito ao devido processo legal, ao contraditório, ao duplo grau de jurisdição etc. A finalidade era que os conflitos deixassem de ser resolvidos pelas próprias mãos e passassem a ser resolvidos pelo Poder Judiciário, através de seus órgãos competentes. Porém, a grande quantidade de processos acabou por abarrotar o sistema judiciário, tornando este lento e as decisões demoradas. A solução para isso foi a criação de métodos alternativos e práticos para a solução de conflitos, são eles: a Mediação, a Conciliação e a Arbitragem. O presente projeto de pesquisa estudará a dogmática do tema "MEDIAÇÃO, CONCILIAÇÃO E ARBITRAGEM NO NOVO CÓDIGO DE PROCESSO CIVIL", sob a perspectiva da nova Lei do Código de Processo Civil. A problemática imposta pelo projeto de pesquisa entabulado justifica-se pela predominância de um modelo tecnicista e instrumental para uma nova era de desjudicialização dos conflitos de interesses.

\section{Jurisdição: conceito e evolução}

É através da função legislativa que o Estado estabelece a ordem na sociedade, fixando preventivamente as normas que deverão ser respeitadas pelos homens na solução de seus conflitos, perante a sociedade. O ordenamento jurídico brasileiro, composto por todas as leis de nosso país, define aos cidadãos seus direitos e deveres, sendo que estes devem respeitá-lo, visando, dessa forma, o bem comum e a pacificação social. O dever de respeitar as normas impostas pelo Estado se baseia no fato de que nós escolhemos os mandatários que nos representam, e estes legislam em nosso nome, de acordo com o que a sociedade anseia. De forma geral as normas são cumpridas; aos que não cumprem cabe ao Estado adotar medidas de coação, 
sempre visando, além da punição pelo ato reprovado pela sociedade, a reinserção do indivíduo à sociedade. Nesses casos é do Estado a função de punir, até mesmo para que não se torne normal o descumprimento das leis. Sabe-se que o conceito de Estado muito mudou durante os diferentes períodos históricos. Nos primórdios da civilização este era fraco e limitava-se a definir os direitos. Os conflitos existentes eram resolvidos mediante a imposição da vontade do mais forte sobre o mais fraco, ação classificada pela doutrina como autotutela ou justiça pelas próprias mãos. Esse método usado para solucionar os conflitos era fraco e incapaz de gerar a paz social desejada, não garantindo a justiça, e sim a vitória do mais forte. Referindo-se à crise da justiça, ADA PELLEGRINI GRINOVER citada por Marco Aurélio Gastaldi Buzzi frisa, "o interesse pela mediação e pela conciliação, e a importância de que as vias consensuais se revistam na sociedade contemporânea levaram ao renascer do instituto em toda parte" ${ }^{1}$ Assim, outras formas surgiram, como a autocomposição, onde um, ou ambos litigantes, espontaneamente sacrificava interesse próprio, total ou parcialmente, com escopo de solucionar o conflito. Contudo, a autocomposição nunca resolvia um problema por completo, e os indivíduos, de alguma forma, tinham que abrir mão daquilo que acreditavam ser direitos seus. Passaram, então, a preferir a solução amigável e imparcial através de árbitros, pessoas de confiança mútua a quem os litigantes conferiam a decisão do conflito. Essa interferência, na maior parte das vezes, era confiada aos sacerdotes, que garantiam soluções acertadas de acordo com a vontade dos deuses; ou mesmo aos anciãos, que conheciam os costumes do grupo social. Somente mais tarde, com o fortalecimento do Estado, este conseguiu impor-se aos particulares quanto à resolução dos conflitos. A arbitragem, antes facultativa, passou a ser obrigatória, sendo o Estado o responsável por designar o árbitro. Inclusive, para evitar decisões subjetivas, este passou também a estabelecer critérios vinculativos aos árbitros, surgindo o papel do legislador. Modernamente, a jurisdição, segundo Humberto Theodoro Júnior, é o poder de formular e fazer atuar praticamente a regra jurídica concreta que disciplina determinada situação jurídica. Importante ressaltar que não são todos os conflitos de interesse que se compõem por meio da jurisdição, mas apenas aqueles que configuram a lide, ou seja, um conflito de interesses qualificados por uma pretensão resistida. Tendo a Jurisdição como fim à resolução de conflitos como dispõe Humberto Teodoro Júnior, "o fim do processo é a entrega da prestação jurisdicional, que satisfaz à tutela jurídica a que se obrigou o Estado ao assumir o monopólio da Justiça". Ou seja, a jurisdição tem como objetivo a eliminação do conflito de interesses que ameaça a paz social. Como poder ou função estatal, a jurisdição é una e abrange todos os litígios que se possam instaurar. Porém, é necessário especialização dos 
julgadores, assim como das próprias leis que regulam a atividade jurisdicional. Aparecem assim as várias ramificações da instrumentalidade do Direito, como o Processo Penal, Processo Civil, Processo Trabalhista etc. Segundo o entendimento de Antônio Carlos de Araújo Cintra, Ada Pellegrini Grinover e Cândido Rangel Dinamarco (1998, p-52), a jurisdição tem como características o caráter substitutivo, sendo que o Estado age de modo secundário, exercendo um ato em substituição às atividades daqueles que estão envolvidos no conflito; o papel de atividade estatal provocada, pois o acesso aos órgãos da jurisdição fica entregue ao poder dispositivo do interessado, sendo aqueles inertes; por fim, a característica da definitividade, ou seja, como coloca os referidos autores, "um conflito interindividual só se considera solucionado para sempre, sem que se possa voltar a discuti-lo, depois que tiver sido apreciado e julgado pelos órgãos jurisdicionais: a última palavra cabe ao Judiciário". Já Humberto Teodoro Júnior (1997, p-537) caracteriza a jurisdição como atividade secundária, instrumental, declarativa, desinteressada e provocada. Secundária porque o Estado realiza uma atividade que deveria ter sido primariamente exercida, de maneira pacífica, pelos próprios sujeitos da relação jurídica; instrumental, visto que considera como objetivo principal da jurisdição dar atuação prática às regras do direito; declarativa, pois exercita a lei nascida anteriormente ao pedido da tutela jurídica estatal, feito pela parte no processo; desinteressada no sentido de que o juiz se mantém distante dos interessados, sendo sua atividade subordinada exclusivamente à lei; por fim, provocada, porque a jurisdição espera ser provocada pela parte insatisfeita. Desse modo, levando em consideração os pontos comuns dos renomados autores e tendo a jurisdição como atividade estatal provocada, com objeto de litígio disponível, pode a lide encontrar soluções por outros caminhos que não um longo processo. A solução pode se dar por meios de auto composição de litígios (mediação e conciliação) ou por decisão de pessoas estranhas ao Poder Judiciário (árbitros). Trata-se dos meios alternativos de resolução de conflitos - mediação, conciliação e arbitragem - que, embora muitas vezes usados como sinônimos possuem suas características definidoras que os tornam únicos no âmbito da resolução de conflitos.

\section{Da Conciliação e da Mediação na nova Lei}

Conciliação e mediação são formas de resolução de conflitos em que um terceiro intervém com a função de auxiliar as partes na autocomposição do litígio. Diferentemente da arbitragem, nestes ao terceiro não cabe resolver o problema, tão somente auxiliar na resolução deste. Coloca Didier Jr. (2015 pág. 275) que ambos os métodos são exemplos da sigla inglesa ADR (em português: solução alternativa de controvérsias), que contrapõem a solução de conflitos pela 
jurisdição estatal. A diferença entre tais meios, porém, é sutil. De acordo com os $\S \S 20$ e 3 do artigo 165 do novo CPC, a audiência será de conciliação nos casos em que não houver vínculo anterior entre as partes e será de mediação caso esse vínculo seja existente.

§2ㅇ O conciliador, que atuará preferencialmente nos casos em que não houver vínculo anterior entre as partes, poderá sugerir soluções para o litígio, sendo vedada a utilização de qualquer tipo de constrangimento ou intimidação para que as partes conciliem; §3으 O mediador, que atuará preferencialmente nos casos em que houver vínculo anterior entre as partes, auxiliará aos interessados a compreender as questões e os interesses em conflito, de modo que eles possam, pelo reestabelecimento da comunicação, identificar, por si próprios, soluções consensuais que gerem benefícios mútuos.

Portanto, a Conciliação, assim como a Mediação, é uma forma negocial. O termo, que advém do latim conciliare, quer dizer acerto de ânimos, enquanto que mediare significa dividir ao meio. Conforme dispõe Humberto Theodoro Junior (Curso de Direito Processual Civil, 2014, p. 1598) "A conciliação é, em nosso processo civil, um acordo entre as partes para solucionar o litígio deduzido em juízo. Assemelha-se à transação, mas dela se distingue, porque esta é ato particular das partes e a conciliação é ato processual realizado por provocação e sob mediação do juiz.". Logo, enquanto o conciliador tem um papel mais ativo, podendo sugerir e opinar, na mediação este terceiro é imparcial e neutro, que auxilia o diálogo entre as partes para que cheguem, com autonomia e solidariedade, na construção de uma melhor solução para o problema.

Acerca do papel do mediador e da mediação como um todo, nos bem ensina o professor Fredie Didier Jr. (DIDIER JR, 2015, p.276):

O mediador exerce um papel um tanto diverso. Cabe a ele servir como veículo de comunicação entre os interessados, um facilitador do diálogo entre eles, auxiliando-os a compreender as questões e os interesses em conflito, de modo que eles possam identificar, por si mesmos, soluções consensuais que gerem benefícios mútuos. Na técnica da mediação, o mediador não propõe soluções aos interessados. Ela é por isso mais indicada nos casos em que exista uma relação anterior e permanente entre os interessados, como nos casos de conflitos societários e familiares. A mediação será exitosa quando os envolvidos conseguirem construir a solução negociada do conflito.

Outra semelhança entre os dois institutos é que ambos podem ocorrer extrajudicial ou judicialmente, sendo que no último caso devem ser tidos o conciliador e mediador como auxiliares da justiça, e a eles devem ser aplicadas as regras de impedimento e suspeição (artigo 148, II). Além das regras contidas no Novo Código de Processo Civil, no Brasil, contemporaneamente, a Mediação entre particulares como meio de solucionar controvérsias, também é a possibilidade da 
autocomposição de conflitos no âmbito da Administração Pública. Por um estudo analítico desta nova lei, percebe-se o intuito do legislador em criar parâmetros sobre o procedimento mediatório, seus agentes, promotores e os limites que todos deverão obedecer. O parágrafo único do art. 1으 da lei 13.140/2015 nos dá um conceito de mediação que deve nos pautar durante todo o estudo acerca do tema e o verdadeiro papel do mediador. Assim leciona o art. 1으 da referida lei e seu parágrafo único:

Art. 10 Esta Lei dispõe sobre a mediação como meio de solução de controvérsias entre particulares e sobre a autocomposição de conflitos no âmbito da administração pública.

Parágrafo único. Considera-se mediação a atividade técnica exercida por terceiro imparcial sem poder decisório, que, escolhido ou aceito pelas partes, as auxilia e estimula a identificar ou desenvolver soluções consensuais para a controvérsia.

Como institutos jurídicos, a Mediação e a Conciliação devem ser norteadas por princípios, e é isso o que nos traz o novo Código de Processo Civil, em seu artigo 166, e a Lei da Mediação, em seu artigo 2‥ O novo C.P.C. traz os princípios da independência, da imparcialidade, do autorregramento da vontade, da normalização do conflito, da confidencialidade, da oralidade, da informalidade e da decisão informada:

§1으 A confidencialidade estende-se a todas as informações produzidas no curso do procedimento, cujo teor não poderá ser utilizado para fim diverso daquele previsto por expressa deliberação das partes. §2 Em razão do dever de sigilo, inerente às suas funções, o mediador e o conciliador, assim como os membros de suas equipes, não poderão divulgar ou depor acerca de fatos ou elementos oriundos da conciliação ou da mediação. §3으 Admite-se a aplicação de técnicas negociais, com o objetivo de proporcionar ambiente favorável à autocomposição. §4ㅇ A mediação e a conciliação serão regidas conforme a livre autonomia dos interessados, inclusive no que diz respeito à definição das regras procedimentais.

O princípio da independência é quanto ao mediador/conciliador, que deve atuar com liberdade, sem qualquer pressão interna ou externa, conforme artigo 1ํ, inciso V, do Código de Ética dos Conciliadores e Mediadores Judiciais:

$\mathrm{V}$ - Independência e autonomia - dever de atuar com liberdade, sem sofrer qualquer pressão interna ou externa, sendo permitido recusar, suspender ou interromper a sessão se ausentes as condições necessárias para seu bom desenvolvimento, tampouco havendo dever de redigir acordo ilegal ou inexequível; 
A imparcialidade (§3ำ, art. 166), é indispensável, pois mediador e conciliador não podem ter qualquer espécie de interesse no conflito. Assim como no processo judicial se requer que o magistrado seja imparcial, na mediação se exige que o mediador também se faça, com escopo de que este exerça suas funções de forma objetiva, não havendo preferências por nenhuma das partes. O autorregramento da vontade refere-se à liberdade das partes em decidir a melhor solução para o conflito (§4ำ, art. 166). O princípio da confidencialidade traz a segurança aos interessados de que as informações ali debatidas não servirão para outra coisa senão para o que eles próprios deliberaram ( $\S \S 1$ e 2으, art. 166). A oralidade e informalidade trazem a característica principal desses métodos de resolução de conflitos, coloca Didier Jr. que "ambos dão a este processo mais "leveza", sem o ritual e a simbologia próprios da atuação jurisdicional". O artigo 166, CPP, finaliza com o princípio da decisão informada, que condiciona a resolução do conflito à correta compreensão do problema e das consequências do acordo. Contudo, a Lei da Mediação (13.140/2015), traz, além destes, os princípios da isonomia entre as partes, da busca do consenso e da boa-fé. O princípio da isonomia, presente também numa relação jurídica processual, deve prevalecer no processo mediatório. Deve-se guardar o mesmo tratamento a ambas as partes, de forma igualitária e equilibrada, uma vez que todos iguais perante a lei. Unido ao princípio da autonomia da vontade das partes está o princípio da busca pelo consenso, pois, analisando o procedimento mediatório, conclui-se que, sendo as partes autônomas no que se refere à proclamação de suas vontades, logo nascerá um consenso entre as mesmas, frutificando o trabalho do mediador. Derradeiro princípio que norteia a mediação está elencado no artigo 2ำ da Lei 13.140/15, que é o da boa-fé. A doutrina aponta harmonicamente que a origem da boa-fé reporta ao direito romano, em seu período clássico, denominado "bona fides". Fides é um vocábulo que possui inúmeros significados, podendo ser designado por três situações distintas, como bem nos ensina Ronnie Preuss Duarte: (DUARTE, 2003, p.50).

a) a fides-poder: a fides, nas relações de clientela (formada entre os cliens e o patronus), "implica a existência de pessoas adstritas a certos deveres de lealdade e obediência perante outras, em troca de proteção; b) a fides-promessa: o aspecto relevante da fides-promessa residia na obrigação de respeito à palavra dada, de garantia que se expressava com um gesto formal e que obrigava o envolvido; c)a fides-externa: inicialmente invocava a fé nos tratados internacionais, designadamente aquele se seguiu à primeira guerra púnica, entre Roma e Cartago. Posteriormente, a fides-externa nada mais significaria do que a imposição da supremacia do poderio romano, após a rendição por meio da delitio in fidem. 
Assim, havendo o mínimo de ma-fé no procedimento mediatório, infere-se que a existência de confiabilidade foi abalada, confundindo-se aí a real expectativa da mediação, ou seja, que as partes cheguem a um consenso, amparadas pela verdade.

Referindo-se a um dos meios alternativos, como dado exemplificativo - os Juizados Especiais, afirma Fernando da Costa Tourinho Neto e Joel Dias Figueira Júnior, ambos citados:

(...) essa nova forma de prestar jurisdição significa, antes de tudo, um avanço de origem eminentemente constitucional, que vem dar guarida aos antigos anseios de todos os cidadãos, especialmente aos da população menos abastada, de uma justiça apta a proporcionar uma prestação de tutela simples, rápida, econômica e segura, capaz de levar à liberação da indesejável litigiosidade contida. Em outros termos, trata-se, em última análise, de mecanismo hábil na ampliação do acesso à ordem jurídica justa. ${ }^{2}$

Uma vez efetivado o acordo por meio da conciliação ou da mediação, lavra-se termo e o juiz profere sentença homologatória, que extingue o processo também com solução de mérito, ou seja, com o mesmo valor de uma sentença, como define o artigo $334 \$ 11$ do novo Código de Processo Civil.

Têm-se também o instituto da arbitragem que é caracterizada pela resolução do conflito através de um terceiro que dará a decisão, não investido porém nas funções de magistrado; regulada pela Lei no. 13.140 de 26 de junho de 2015. Diferente da conciliação, aqui intermediador decide o conflito e a sua decisão equipara-se à sentença convencional do Poder Judiciário, ou seja, faz obrigação entre as partes. Por não se realizar dentro da esfera estatal, é definido pelas partes o método a ser adotado pelas partes durante o procedimento da arbitragem, assim como também escolhem o árbitro e o prazo de finalização da resolução do conflito.

\section{CONCLUSÃO}

Diante do exposto, a evolução científica processual destaca a necessidade de um novo paradigma para como os métodos alternativos de resolução de conflitos, há muito estudado durante as duas últimas décadas, porém, sem o merecido destaque e aprimoradas políticas públicas para a implantação e implementação desse novo modelo judicial. O fim almejado de pacificação de conflitos de interesses justificam a previsão legislativa no texto de lei do Novo Código de Processo Civil, restam dúvidas, porém, acerca da real viabilidade, implementação, organização e eficácia da lei ou efetividade da tutela pretendida pelo jurisdicionado. Tal 
problemática merece um novo olhar e novas pesquisas sobre a "evolução" científica do objeto de estudo, apresentando os resultados parciais, de um projeto de pesquisa.

\section{REFERÊNCIAS}

ALVIM, Arruda Eduardo. ASSIS, Araken de. Comentários ao Código de Processo Civil. 3a edição revista e atualizada. Revista dos Tribunais Thomson Reuters, São Paulo, 2014.

CAPPELLETTI, Mauro; GARTH, Bryant. Acesso à Justiça. Trad. Ellen Gracie Northfleet. Porto Alegre: Sergio Antonio Fabris, 2002.

COMOGLIO, L.P. 1988. Etica e tecnica del "giusto processo". Torino, G. Giappichelli.'giusto processo' civile in Italia. Revista de Processo, II, 2004-a, 116:154-158.

DIDIER Jr, Fredie. Curso de direito processual civil: introdução

DUARTE, Ronnie Press. Boa fé, abuso de direito e o novo código civil brasileiro. Revista dos Tribunais/vol. 817/2003 - p. 50-78. Nov.2003.

GONÇALVES, Marcus Vinícius Rios. Direito Processual Civil Esquematizado. São Paulo: Editora Saraiva, 1ae ed., vol. único, 2011.

GONÇALVES, Fernando. Abertura do III Curso de Formação de Multiplicadores em Mediação e Técnicas Autocompositivas. *Ministro do Superior Tribunal de Justiça e Diretor-Geral da Enfam, Cidade Belo Horizonte, ano 2013.

GRINOVER, Ada Pelegrini. Teoria Geral do Processo. Editora Malheiros, ano 1998, p-52.

JÚNIOR, Humberto Theodoro. Curso de Direito Processual Civil. Rio de Janeiro: Editora Forense. vol.1, 54a ed., 2013, p. 263.. In: MARQUES, José Frederico. Manual de Direito Processual Civil, 1ạed., Campinas: Bookseller, 1997, v. III, n.537.

RODRIGUES, José Renato. Breves Considerações sobre alguns pontos da solução conciliatória de conflitos no Judiciário, Editora Impetrus, Cidade São Paulo, ano 2012.

SEVERINO, Antonio Joaquim. Metodologia do Trabalho Científico. Editora Cortez, Rio de Janeiro, ano 2014.

WAMBIER, Luiz Rodrigues. Curso Avançado de Processo Civil. São Paulo: Editora Revista dos Tribunais, vol.1, 8 ed., 2006.

WAMBIER, Teresa Arruda Alvim. Parte Geral ao direito processual civil, parte geral e processo de conhecimento. 17aa ed. - Salvador: Ed. Jus Podevim, 2015.e Processo de Conhecimento. Vol. 1, 2a edição. Revista dos Tribunais, São Paulo, 2011. 